\title{
Blood monocyte counts as a potential prognostic marker for idiopathic pulmonary fibrosis: analysis from the Australian IPF registry
}

To the Editor:

Idiopathic pulmonary fibrosis (IPF) is a chronic, progressive, fibrosing lung disease that leads to unrelenting dyspnoea and chronic cough, and ultimately respiratory failure [1]. IPF is characterised by a variable disease course that remains difficult to predict for an individual at diagnosis [2]. In the current era, with the advent of anti-fibrotic therapy which can slow disease progression, it is increasingly important to identify patients with early disease and to target those patients who are at most risk of rapid decline [3]. However, despite multiple studies proposing novel potential prognostic biomarkers, the current American Thoracic Society/European Respiratory Society/Japanese Respiratory Society/Latin American Thoracic Society guideline statements dismissed the use of these biomarkers except in a research capacity $[3,4]$.

Recently, ScOTт et al. [5] have suggested that peripheral blood monocyte count may be a powerful biomarker capable of predicting poorer prognosis amongst IPF patients. In a retrospective analysis using transcriptome microarray data, the investigators found that estimated CD14+ monocyte percentages above the mean were associated with shorter transplant-free survival times. Using a threshold monocyte value of $0.95 \times 10^{3}$ per $\mu \mathrm{L}$ or greater, the investigators were able to validate their exploratory analysis using several independent cohorts. Higher absolute CD14+ monocyte counts were found in the COMET cohort in patients who had progressive disease and in those that were classified as high-risk in the Yale cohort. Higher absolute monocyte counts were found to be associated with increased risk of mortality in several other larger validation cohorts. This finding remained significant following adjustment for forced vital capacity (FVC) and the gender, age and physiology index in each of the COMET, Stanford and Northwestern cohorts.

We sought to reproduce this finding using data from the Australian IPF Registry (AIPFR). The national AIPFR is investigator-led, prospectively acquired and was established in 2012 with the goal of facilitating research into IPF as well as to provide further insight into the epidemiology and management of IPF in Australia [6]. Baseline routine full blood count tests with cell differentials performed on patients recruited into the registry were extracted for analysis. A total of 231 patients from three Australian states (New South Wales, Victoria and South Australia) were included.

Clinical data had been prospectively entered into the Registry with a follow up duration of 2.4 (1.3-3.3) years. The majority of patients were male $(71 \%)$ with a mean \pm sD age of $69.9 \pm 8.3$ years. Patients were found initially to have mild to moderate disease with a mean FVC of $80.3 \pm 22.0 \%$ predicted and a mean diffusing capacity of the lung for carbon monoxide of $48.2 \pm 16.8 \%$ predicted. Mean blood monocyte counts were significantly higher in the 75 patients who died compared to the 156 patients who remained alive after the follow-up period, although the difference was clinically small (0.66 (0.5-0.9) versus 0.6 (0.4$0.7) \times 10^{3}$ per $\mu \mathrm{L} ; \mathrm{p}=0.006$ ). Additionally, neutrophil and total leukocyte counts were also significantly higher in the deceased patient cohort. A Cox proportional hazards model was used to evaluate the effect of an elevated serum monocyte count on survival of the IPF registry patients. 22 patients had monocyte

@ERSpublications

Blood monocytes have been recently proposed as a potential prognostic marker for IPF. Data from the Australian IPF registry have shown that elevated monocytes, neutrophils and total leukocytes significantly predict poorer survival in IPF patients. http://bit.ly/38GP7f0

Cite this article as: Teoh AKY, Jo HE, Chambers DC, et al. Blood monocyte counts as a potential prognostic marker for idiopathic pulmonary fibrosis: analysis from the Australian IPF registry. Eur Respir J 2020; 55: 1901855 [https://doi.org/10.1183/13993003.01855-2019]. 


\begin{tabular}{|c|c|c|c|}
\hline & Hazard ratio & $95 \% \mathrm{Cl}$ & p-value \\
\hline Age & 1.0 & $1.0-1.1$ & 0.11 \\
\hline Gender & 1.1 & $0.7-1.9$ & 0.64 \\
\hline FVC $\%{ }^{\#}$ & 0.7 & $0.7-0.9$ & $<0.0001$ \\
\hline $\mathrm{D}_{\text {LCO }}{ }^{\#}$ & 0.6 & $0.5-0.8$ & $<0.0001$ \\
\hline Monocytes ${ }^{ף}$ & 3.2 & $1.4-7.4$ & 0.005 \\
\hline High monocytes $\left(\geqslant 0.95 \times 10^{9}\right.$ per $\left.L\right)$ & 2.4 & $1.3-4.4$ & 0.004 \\
\hline Neutrophils & 1.2 & $1.1-1.2$ & $<0.0001$ \\
\hline High neutrophils $\left(\geqslant 7 \times 10^{9}\right.$ per $\left.L\right)$ & 2.5 & $1.5-4.1$ & $<0.0001$ \\
\hline Total WCC & 1.2 & $1.1-1.2$ & $<0.0001$ \\
\hline High total WCC ( $\geqslant 10 \times 10^{9}$ per L) & 2.6 & $1.6-4.1$ & $<0.0001$ \\
\hline
\end{tabular}

FVC: forced vital capacity; DLCO: diffusing capacity of the lung for carbon monoxide; WCC: white cell count. ${ }^{\#}$ : every $10 \%$ change. ": continuous variable.

counts equal to or greater than the value of $0.95 \times 10^{9}$ per L, used by SсотT et al. [5]. The Australian standardised upper limit of normal values for neutrophils and total leukocyte counts were used as threshold values at $7 \times 10^{9}$ per $\mathrm{L}$ and $10 \times 10^{9}$ per $\mathrm{L}$ respectively. There were 44 and 50 patients with neutrophil and total leukocyte counts equal or greater than the threshold values respectively. Univariate analysis for mortality showed that elevated monocyte, neutrophil and total leukocyte counts were associated with decreased survival (table 1). Following a multivariate analysis adjusting for age, gender and baseline FVC \% predicted, elevated monocyte count remained a significant predictor for poorer survival (HR 2.36, 95\% CI 1.18-4.70; p=0.02). However, elevated neutrophil and total leukocyte counts also remained independently associated with poorer outcomes (HR 2.10, 95\% CI 1.22-3.62; p=0.008; and HR 2.07, 95\% CI 1.23-3.50; $\mathrm{p}=0.006$; respectively).

The limitation of our study relates to the real-world nature of the registry, in which peripheral blood sampling was dictated by individual physicians and was not necessarily the patients' true baseline at diagnosis. Additionally, there was limited data on the prescription of anti-fibrotic therapy as these agents were not readily available to the Australian public on subsidised government-funded programmes prior to 2016. Despite this, one advantage of our registry data is the availability of relatively longer follow-up time and mortality data of IPF patients recruited.

Our findings add further validity to the notion that a routinely measured blood cell population may have a potential as a biomarker, with elevated monocyte counts suggesting a worse prognosis in the individual patient presenting with IPF. Both monocytes and neutrophils have been postulated to play a role in the pathogenesis of IPF and have also been shown to correlate with disease progression [7-9]. We echo the commentary by KREUTER and MAHER [10] in agreeing that there is a need for further detailed studies to provide better mechanistic insights into the role that monocytes and neutrophils play in IPF. Given the consistency of the association across several diverse cohorts, including ours, a crucial next step is to accurately delineate the nature of the monocytosis in poor prognosis IPF.

Alan K.Y. Teoh ${ }^{1,2,3}$, Helen E. Jo ${ }^{1,2,3}$, Daniel C. Chambers ${ }^{3,4,5}$, Karen Symons ${ }^{6}$, Eugene H. Walters ${ }^{3,7}$, Nicole S. Goh ${ }^{3,8}$, Ian Glaspole $\oplus^{3,9}$, Wendy Cooper ${ }^{1,2}$, Paul Reynolds ${ }^{3,10}$, Yuben Moodley, ${ }^{3,1}$ and Tamera J. Corte ${ }^{1,2,3}$ ${ }^{1}$ Royal Prince Alfred Hospital, Camperdown, Australia. ${ }^{2}$ University of Sydney, Sydney, Australia. ${ }^{3}$ Centre of Research Excellence in Pulmonary Fibrosis, Camperdown, Australia. ${ }^{4}$ The Prince Charles Hospital, Brisbane, Australia. ${ }^{5}$ University of Queensland, Brisbane, Australia. ${ }^{6}$ Lung Foundation Australia, Milton, Australia. ${ }^{7}$ University of Tasmania, Hobart, Australia. ${ }^{8}$ The Austin Hospital, Heidelberg, Australia. ${ }^{9}$ The Alfred Hospital, Melbourne, Australia. ${ }^{10}$ Royal Adelaide Hospital, Adelaide, Australia. ${ }^{11}$ Fiona Stanley Hospital, Murdoch, Australia.

Correspondence: Alan K.Y. Teoh, Royal Prince Alfred Hospital, Dept of Respiratory and Sleep Medicine, 50 Missenden Road, Camperdown, New South Wales 2050, Australia. E-mail: alan_tky@yahoo.com

Received: 19 Sept 2019 | Accepted after revision: 6 Dec 2019

Conflict of interest: A.K.Y. Teoh reports personal fees from Roche and Boehringer, outside the submitted work. H.E. Jo has nothing to disclose. D.C. Chambers has nothing to disclose. K. Symons has nothing to disclose. E.H. Walters has nothing to disclose. N.S. Goh has nothing to disclose. I. Glaspole reports personal fees from Boehringer Ingelheim, Avalyn and Roche, outside the submitted work. W. Cooper has nothing to disclose. P. Reynolds has nothing to disclose. Y. Moodley reports advisory board membership for Roche and Boehringer Ingelheim, outside the submitted work. T.J. Corte reports grants, personal fees for advisory board work and lectures, and travel support from Boehringer, grants and personal fees for advisory board work and lectures from Roche, grants from Galapagos, Actelion, Bayer and Sanofi, personal fees for advisory board work from AstraZeneca, outside the submitted work. 


\section{References}

1 Raghu G, Collard HR, Egan JJ, et al. An official ATS/ERS/JRS/ALAT statement: idiopathic pulmonary fibrosis: evidence-based guidelines for diagnosis and management. Am J Respir Crit Care Med 2011; 183: 788-824.

2 Ley B, Collard HR, King TE, Jr. Clinical course and prediction of survival in idiopathic pulmonary fibrosis. Am J Respir Crit Care Med 2011; 183: 431-440.

3 Jo HE, Glaspole I, Moodley Y, et al. Disease progression in idiopathic pulmonary fibrosis with mild physiological impairment: analysis from the Australian IPF registry. BMC Pulm Med 2018; 18: 19.

4 Raghu G, Remy-Jardin M, Myers JL, et al. Diagnosis of idiopathic pulmonary fibrosis. An official ATS/ERS/JRS/ ALAT clinical practice guideline. Am J Respir Crit Care Med 2018; 198: e44-e68.

5 Scott MKD, Quinn K, Li Q, et al. Increased monocyte count as a cellular biomarker for poor outcomes in fibrotic diseases: a retrospective, multicentre cohort study. Lancet Respir Med 2019; 7: 497-508.

6 Moodley Y, Goh N, Glaspole I, et al. Australian Idiopathic Pulmonary Fibrosis Registry: vital lessons from a national prospective collaborative project. Respirology 2014; 19: 1088-1091.

7 Moore BB, Fry C, Zhou Y, et al. Inflammatory leukocyte phenotypes correlate with disease progression in idiopathic pulmonary fibrosis. Front Med 2014; 1: 00056

8 Gregory AD, Kliment CR, Metz HE, et al. Neutrophil elastase promotes myofibroblast differentiation in lung fibrosis. J Leukoc Biol 2015; 98: 143-152.

9 Guilliams M, Mildner A, Yona S. Developmental and functional heterogeneity of monocytes. Immunity 2018; 49: 595-613.

10 Kreuter M, Maher TM. Can monocytes predict prognosis of idiopathic pulmonary fibrosis? Lancet Respir Med 2019; 7: 467-469. 